\title{
La impostura y el juego de la traducción
}

Marina FE

Universidad Nacional Autónoma de México

\author{
IMPOSTURA: imputación falsa y maliciosa. // Fingimiento o \\ engaño con apariencia de verdad. \\ Real Academia Española, Diccionario de la lengua española
}

No parece necesario discutir si la traducción de textos literarios es posible o si no lo es pues sabemos que desde hace siglos no ha dejado de hacerse y porque, sin la traducción, lo que pretende ser una cultura universal (y que quizás apenas merece llamarse cultura occidental) no podría nunca haberlo sido: la idea misma de 'universalidad' sería inconcebible sin la traducción de textos fundamentales como, para usar un solo ejemplo, la Biblia. Sin embargo, la duda acerca de la plausibilidad de la traducción literaria sigue acosándonos. Ya que ¿no es acaso toda traducción un falseamiento, una mueca del texto original? De acuerdo con Walter Benjamin, un texto original es siempre potencialmente traducible y la tarea del traductor "consiste en encontrar en la lengua a la que se traduce, una actitud [intención] que pueda despertar en dicha lengua un eco del original". ${ }^{1}$ Con esto, me parece, Benjamin plantea el problema de la traducción literaria aunque no necesariamente lo resuelve, pues ¿qué podemos entender por "actitud" o "intención" y por "eco"? $\mathrm{Si}$ un texto literario aparece como terminado y completo (puesto que un poema, una novela, un cuento, son como son una vez que existen), el traductor se ve obligado a empezar de nuevo, a "abrirlo", cosa que en sí misma puede parecer una aberración: como el eco que repite, deforma y parece burlarse de aquella voz que tendría que haberse escuchado una única ocasión, la traducción sería, en este sentido, sólo la traza de otro texto, su metamorfosis. (No es lo mismo "To enter in these bonds, is to

1 Walter BENJAMIN, “The Task of the Translator", en Illuminations. Nueva York, Schocken Books, 1969, p. 69. 
be free; / Then where my hand is set, my seal shall be" de la Elegía XIX de John Donne, que "Mi libertad alcanzo entre tus lazos: / Lo que toco, mis manos lo han sellado" de la traducción de Octavio Paz.)

Entre el original y la traducción existe, inevitablemente, una distancia, un vacío, una diferencia; la traducción nos remite a la presencia de un tex to que aquí, paradójicamente, está ausente. La comunicación estética depende siempre de su realización, de su materialización singular, y en este sentido el texto traducido nunca será una réplica fiel del texto original. Sin embargo, para Benjamin, el lenguaje parece contener una esencia, un núcleo poético puro, y éste parece ser el problema —más que del lenguaje - de Benjamin y muchos más: el aferrarse a una noción del texto como "esencial", a la idea de que los trabajos artísticos esconden un significado pleno, único, autosuficiente y autónomo, un centro que sólo puede pertenecer al texto y al lenguaje que lo contiene y que, por 10 tanto, no puede traducirse. ¿Cómo salir entonces de esta encrucijada? Me parece que el mismo Benjamin puede sernos de utilidad si privilegiamos su idea sobre la relación de la traducción con la filosofía y la crítica. En la medida en que el traductor es antes que nada un lector, la traducción representa necesariamente una lectura peculiar del texto original. Pero ¿qué tipo de lector seria un buen traductor? En primera instancia tendría que ser, sin lugar a duda, un lector crítico, ya que sólo una lectura crítica que parta del análisis cuidadoso no sólo de los "contenidos" de un texto sino de su materialidad misma, del uso del lenguaje como tal, hace posible que más que una paráfrasis o una imitación, la traducción sea una re-creación.

¿Cómo entender dicha actitud crítica necesaria para la traducción creativa o recreativa? En mi opinión, la idea a la que hacía referencia antes acerca de la plenitud de sentido de un texto literario aparece como el principal obstáculo. Una traducción que pretendiera interpretar hermenéuticamente un texto literario no haría, estoy segura, más que empobrecerlo, limitándolo a un significado único y fijo, subordinando la abundancia de su lenguaje a la precariedad de un contenido. Quienes reconocen que el trabajo de la escritura es antes que nada una técnica saben bien que el lenguaje se resiste a la estabilidad, que su libertad de juego hace imposible cualquier intento por inmovilizarlo, por convertirlo en sistema cerrado (de ahí la dificultad de dejar a las máquinas el trabajo de traducir). Este libre juego del lenguaje consiste en un desplazamiento interminable de sentidos, en una suerte de errancia. "No se trata - dice Octavio Paz- de construir con signos móviles un texto inamovible, sino de desmontar los elementos de ese texto, poner de 
nuevo en circulación los signos y devolverlos al lenguaje". ${ }^{2}$ Asi, una lectura crítica, desconstructiva, sería entonces aquella que se mantuviera cerca del texto que pretende analizar o criticar, sin perder de vista la diferencia, diferencia en el sentido más convencional y también en el sentido derrideano de desplazamiento, de translación: ese juego 0 interjuego entre presencia y ausencia, entre lo que se dice y lo que no se dice, entre lo que pretende decirse y no logra ser dicho o se dice sin querer; donde el sentido nunca está realmente presente sino diferido, desplazado incesantemente, sin tener lugar.

Pero Benjamin parece estar obsesionado por el "lenguaje puro" y no es gratuito que cite (en francés) a Mallarmé:

Les langues imparfaites en cela que plusieurs, manque la supreme: penser étant écrire sans accesoires, ni chuchotement mais tacite encore l'immortelle parole, la diversité, sur terre, des idiomes empeche personne de proférer les mots que, sinon se trouveraient, par une frappe unique, elle-même matériallement la vérité. ${ }^{3}$

No puedo detenerme aquí en los problemas de traducción que presenta este mismo fragmento sino simplemente señalar que, con esta cita, Benjamin pretende apoyar su creencia en una lengua ideal, perfecta, donde parecería estar contenida nada menos que "la verdad"; una lenguavasija, un recipiente original del cual, después de Babel, no quedarían más que fragmentos. No obstante, aunque resulte problemático compartir ciertas creencias, la metáfora de la vasija que usa el mismo Benjamin puede sernos de utilidad si imaginamos que, ya sea que se trate de una "primera" lengua (prebabélica), o de una de tantas lenguas "imperfectas" (posbabélicas) que pueden, en virtud misma de su imperfección, ser traducidas, la vasija siempre habría estado rota, o más bien vacía.

Si estamos de acuerdo en que la verdad (o el sentido) no tiene lugar, se complica, es cierto, nuestro acercamiento a un texto que, desde esta perspectiva crítica, parece escurrirse como agua entre los dedos, pero al mismo tiempo se abren muchas puertas al trabajo de traducción que

2 Octavio PAZ, Traducción: literatura y literalidad. Barcelona, Tusquets, 1980 (Cuadernos marginales, 18).

3 "Las lenguas imperfectas por ser tantas, falta la suprema: pensar es escribir sin accesorios, ni susurro sino tácita todavía la palabra inmortal, la diversidad, sobre la tierra, de los idiomas impide que nadie profiera las palabras que, si no se encontrarían, por un único golpe, en sí misma materialmente la verdad". (Apud Walter BENJAMIN, op. cit., p. 77. La traducción es mía.) 
aparece también, a su vez, como un "libre juego", como "recreación". Dice Haroldo de Campos en su ensayo "De la traducción como creación y como crítica":

La traducción de la poesia (o de una prosa con un grado igual de dificultad) es antes que nada una experiencia de introspección en el mundo y en la técnica del texto a ser traducido. Es como si se desmontara y al mismo tiempo se remontara a la maquina de la creación, aquella endeble belleza aparentemente inaccesible que nos ofrece el producto acabado de una lengua extranjera y que, sin embargo, se muestra susceptible de una vivisección implacable, capaz de removerle las entrañas, para traerla nuevamente a la luz de un cuerpo lingüistico diferente. Por esa misma razón la traducción es crítica. ${ }^{4}$

Así, la belleza oculta (y "endeble") de ese cuerpo o materia que parecía inaccesible, es susceptible de reencarnar gracias a la "implacable vivisección" a la que la somete el traductor (las metáforas quirúrgicas no son mías) al entrar en contacto con el otro, al dialogar con lo otro.

La traducción es entonces el vehículo privilegiado para dicho contacto, para esa recreación o "transcreación" que desnuda al texto aparentemente virginal (las metáforas sexuales sí son mías) que parecía contenerse a sí mismo y encerrar un misterio. No se trata, insisto, de una revelación o de una epifanía, lo que implicaría de nuevo la convicción de que todo texto oculta una verdad, la verdad, sino de la apertura del texto literario que en realidad no oculta nada (o bien lo oculta todo) y cuyo sentido, en todo caso, está siempre en otra parte. Dicha lectura crítica, desacralizante, pondría el énfasis en la no-plenitud del significado y así, el texto abierto, susceptible de ser recreado, sería, en su versión (en subversión) en otra lengua, otro y el mismo texto. "Se tendría entonces, en otra lengua, otra información estética, autónoma, pero ambas estarían vinculadas entre sí por una relación de isomorfia: serían distintas como lenguaje, pero, como los cuerpos isomorfos, se cristalizarian dentro de un mismo sistema". 5 El traductor tendría que ser entonces, en un primer momento, un lector crítico capaz de desmontar o desconstruir el texto a traducir, consciente de la arbitrariedad, de la inestabilidad de los signos del lenguaje, del juego entre la materia que representa y lo representado, de las tensiones de la escritura, de la distancia entre la intención aparente

\footnotetext{
"Haroldo de CAMPOS, “De la traducción como creación y como crítica”, en Quimera, núm. 9-10. Barcelona, julio-agosto, 1981, p. 36.

s Ibid., p. 32.
} 
y su materialización particular. Sería, de acuerdo con Paul de Man, un lector que privilegiara las estrategias retóricas del texto mismo, que tratara de ser "un lector tan riguroso como tuvo que serlo el autor mismo".6

Sin embargo, y ésta me parece la gran paradoja de la traducción, el texto traducido difícilmente puede desprenderse del original, a pesar de haberse convertido en otro texto. Su falla, su impostura, radica justamente en su vínculo especular con el otro al que pretende develar y al lado del cual tiene que convivir casi incestuosamente. Por eso el traductor se abisma en el lenguaje, en una lengua y otra, en un acto de posesión pero también de entrega, de identificación: descubre su voz en la otra voz y su trabajo deja de ser sólo una empresa intelectual para convertirse también en un acto creativo y amoroso. El texto traducido, producto del contacto con el original, queda entonces inseminado por éste y sólo así puede florecer. Como en el teatro, como en el juego del actor que tiene que "traducir" los tonos, las vibraciones de un texto escrito a un lenguaje distinto, gestual, corporal y vocal, en el juego de la traducción es necesario también "identificarse", "compenetrarse", "meterse en la piel" del otro, de eso que parece ocultarse detrás de la máscara de las palabras. Un ejemplo, para seguir usando esta metáfora teatral, es lo que dice Peter Brook refiriéndose al trabajo del actor y que tiene una asombrosa cercanía con el trabajo del traductor: "Actuar [jouer, jugar] plenamente cada imagen... investirse totalmente durante el tiempo en que pasa por la cabeza y por la boca [...] la variedad constante de las imágenes propuestas por el texto, asumida así por la imaginación del actor, asegura al desarrollo del juego [actuación] una densidad extrema, pero una densidad cambiante en relación con la materia del texto" y, continúa más adelante: "una palabra llena un vacío, pero crea otro..."

Aunque las palabras nada oculten, aunque el texto no sea más que una mascarada, una vasija vacía o rota, el traductor, como el actor, debe jugar a que hay algo ahí que es necesario comunicar. Dice George Steiner: "Debemos leer como si el texto frente a nosotros tuviera sentido. Este no sería un sentido único si el texto es un texto serio, si nos hace responder a su fuerza vital [...] No sería un sentido al que se llega por algún proceso determinante 0 automático de acumulación y consenso". $Y$ añade: "cuan-

\footnotetext{
${ }^{6}$ Paul de MAN, The Resistance to Theory. Mineápolis, Universidad de Minesota, 1987, p. 91 .

7 Peter Brook, Timon d'Athènes. Notas de Jean-Pierre Vincent. París, Centre International de Créations Théatrales, 1974, p. 100.
} 
do leemos verdaderamente, cuando la experiencia es la experiencia del sentido, hacemos como si el texto (la pieza musical, la obra de arte), encarnara (la noción está fundada en lo sacramental) una presencia real de significación". ${ }^{8}$ El juego de la traducción consiste asi en dejarse habitar por algo que no está necesariamente presente en el texto que traduciremos, por una ausencia, y en buscar un centro ahi donde sabemos que sólo hay desplazamiento, diseminación... Sin olvidar que lo que está en juego no es realmente la comunicación (de un sentido, de una verdad) -ya que ¿quién podría describir con exactitud lo que una obra artística comunica? - sino aquello que tanto en un texto como en su versión traducida está siempre diferido y resulta, en última instancia, incomunicable y hasta ilegible.

${ }^{8}$ George STEINER, Real Presences. Cambridge, Universidad de Cambridge, 1985. 